\title{
Gamification in the childhood education classroom
}

DOI: $10.46932 / \mathrm{sfjdv2n1-045}$

Received in: November 1st, 2020

Accepted in: December 30th, 2020

Sandra Giménez García

Graduada Educación Infantil

Instituição: RG Formación

Calle Rosalía de Castro, 44, 30107 Murcia

Alba Hernández Nicolás

Graduada Educación Infantil

Instituição: RG Formación

Calle Rosalía de Castro, 44, 30107 Murcia

Marta Garrido Cano

Graduada Educación Infantil

Instituição: RG Formación

Calle Rosalía de Castro, 44, 30107 Murcia

Jose María Rabal Alonso

Profesor ISEN Centro Universitario

Instituição: Universidad de Murcia

Calle Campus Universitario, 12, 30100 Murcia

E-mail: josemaria.rabal@um.es

\begin{abstract}
In this article we will talk about the concept of gamification and its motivating role in the Early Childhood Education classroom. Gamification, as we will see in the development of this article, is a type of learning that will facilitate the internalization of content in a more fun way, generating positive experiences in children. Therefore, the present work is composed of a conceptual clarification of said term, by a differentiation between gamified activity and gaming, and by the fundamental points of gamification. On the other hand, we indicate several tools on how to bring this learning to the classroom and why to bring it, since this methodology will favor learning processes, innovation, fun, productivity and the acquisition of skills.
\end{abstract}

Keywords: Gamification, Early Childhood Education, meaningful learning, motivation, game, didactic.

\section{THEORETICAL FRAMEWORK}

The main objective that we intend to achieve in the development of this article is to make known that every Early Childhood Education teacher must set the game as the main methodology to be carried out in the classrooms.

Gambling is one of the general principles established in Decree 254/2008, of August 1, which establishes the second cycle of Early Childhood Education and in Order ECI 3960/2007, of December 9 
(BOE no. 5, Saturday January 5, 2008), which establishes the curriculum and regulates the organization of Early Childhood Education, where it indicates, in point number 4 of Article 2, that the work methods will be based on experiences, on children's activities and games, which will be applied in an environment of security, affection and trust to promote self-esteem and social integration.

Therefore, starting from the foregoing and knowing that gamification is a learning technique in which own game dynamics are used, thus achieving greater interest on the part of the students, providing meaningful learning and favoring motivation in boys and girls It must be said that according to Eguia and Contreras (2016), talking about gamification is talking about motivation through entertainment and fun. In addition, by bringing gamification to the classroom, we can make students capable of assuming any error as something natural, with the aim of reinforcing their strengths and reducing their weaknesses, understanding any error as learning and managing to end that fear that every child and girl has to be wrong (Fandoz and González, cited in Igados, 2013).

\subsection{WHAT DO WE CALL GAMIFICATION?}

The word gamification comes from the Anglicism gamification. Deterding, Dixon, Khaled and Nacke define it in the article Gamification: Toward a Definition in 2011 as "the use of game designs elements, characteristic for games, in non-game contexts" (Deterding, Dixon, Khaled and Nacke, 2011, p .2). That is, it refers to the use of game design elements in non-game contexts.

We can also highlight the definition that Zichermann (2012) makes of gamification. This defines the term as the use of the elements of the game systems that allow creating experiences in the fields of health, finance, government, education, as well as other branches. Gamification takes all those that are not games, to change them in a creative way to a game, thus giving it a playful sense (Ciganda, 2018, p.11)

To understand what gamification is, it is essential to differentiate between gamification and gamification. Foncubierta and Rodríguez (2014), "recognize the game as something concrete, while gamification is based on didactic content, that is, the elements and thoughts of the game are used to spice up the proposed activities" (Romero and Espinosa, 2019, p.63).

In short, as Romero and Espinosa (2019) affirm: "through a gamified activity, students do not learn through specific games, but rather learn as if they were playing a game" (p.64).

\subsection{WHAT IS A GAME AND WHAT IS A GAMIFIED ACTIVITY?}

Having indicated possible definitions about gamification, it is likely that a question has arisen with this concept. In the previous sections, it has been indicated that game elements must be introduced in the 
activity, but how can we identify the game of a gamified activity? As Foncubierta and Rodriguez (2014) indicate, we can make the following difference: the game as a finished product and which we can recognize as something concrete. While, gamification starts from a didactic content and is what they define as an activity with elements or thoughts of the game. Like Hamari and Koivisto (2013) they state that gamification has the purpose of influencing the behavior of the participants, since it allows the creation of experiences and provides the student with control, autonomy and fun. Simoes (2013: 03) with a gamified activity, «students learn, not by playing specific games, but rather they learn as if they were playing a game»

\subsection{THE FUNDAMENTAL POINTS OF GAMIFICATION}

From our point of view, we can find numerous key points of gamification, but one of them that we consider important is "camouflaging" the learning, the content in the game, since it provides students with a different environment in which they are not they have to worry about making mistakes, just having fun and learning while having fun. According to Foncubierta and Rodríguez (2014), by means of these elements of the game, children dedicate more time to the activity and become more involved in it. It is also interesting to say that video games themselves produce dopamine, a chemical that promotes learning by strengthening neural connections and communications (Johnson, 2013: 23).

Another point that we can highlight is that this same author tells us that educational games have shown in students an increase in socio-emotional skills, that is, better critical reasoning, effective problem solving and teamwork.

On the other hand, as Gibson (2012) indicates, what boy or girl does not like to play? Every day, both children and adults, we face activities that lack motivation and it is a big problem, especially in Early Childhood Education, since it is a stage where play is the main methodological resource to be carried out in the classroom. Therefore, we can say that gamification in our classrooms is a great potential to achieve a good education and involvement in our girls and boys.

Finally, say that gamification has a great influence on technology, since the same word indicates a direct relationship with video games. Foncubierta and Rodríguez (2014), confirm that through gamification, learning spaces can be expanded, as in previous sections we have indicated, an example would be the ClassDojo application, since families and students can work from home or from anywhere another space. 


\subsection{REASONS TO BRING GAMIFICATION TO THE EARLY CHILDHOOD EDUCATION CLASSROOM}

The first reason underlying the development of gamification in the Early Childhood Education classroom is that it favors motivation for learning. Children are passionate about playing, despite this, sometimes the games and / or activities that are proposed are not motivating. Thus, gamification is responsible for introducing motivation in education.

Similarly, gamification allows constant feedback, that is, children are players, they are the main protagonists, which makes them feel involved and make their own decisions while, at the same time, they are progressing and seeing their achievements.

Likewise, gamification gives rise to meaningful learning, a key aspect in the Early Childhood Education stage. This part of what attracts children, stimulating them and promoting said learning.

In addition, it allows the acquisition of autonomy, through the establishment of challenges that children must overcome.

It also promotes digital literacy, that is, the application of game mechanics to school tasks through the use of ICT, an aspect that motivates students and increases their participation (Romero and Espinosa, 2019).

Finally, it is important to note that when developing gamification in the Early Childhood Education stage, we must take into account that students are in the pre-operational stage, in which symbolic play predominates. In addition, they also continue to develop the sensorimotor stage in which active play is essential to achieve development. Therefore, the teacher of this stage must understand gamification as a transversal tool in order to teach different topics at the same time (Ciganda, 2018).

\subsection{HOW TO BRING GAMIFICATION TO THE EARLY CHILDHOOD EDUCATION} CLASSROOM?

There are numerous resources with which we can bring gamification to the Early Childhood Education classrooms, through applications and resources such as the Interactive Whiteboard, we can transport students to a playful world, where fun will always be present. Next, we show you some examples for the Early Childhood Education classroom:

\subsubsection{Kahoot}

It is a tool with which we can create questions and answers in a very intuitive way. Therefore, through the Interactive Whiteboard we can carry out this resource and work, both individually and cooperatively. 
In our classrooms, through new technologies such as tablets, students will be able to work cooperatively, since this becomes a remote control with which they can easily answer questions, while the screen shows them, in the case of Early Childhood Education, the answers in pictures.

At the end of the game, a podium shows by colors (red, yellow, blue and green, the team colors) the score of each one, so that whoever comes closest to the medal will win.

It is an easy-to-use resource that we can take advantage of in the classroom, since, for example, at the end of each didactic unit or project, we can make a compilation of questions and consolidate the knowledge acquired, as well as review.

Image 1. Visualization of the kahoot application

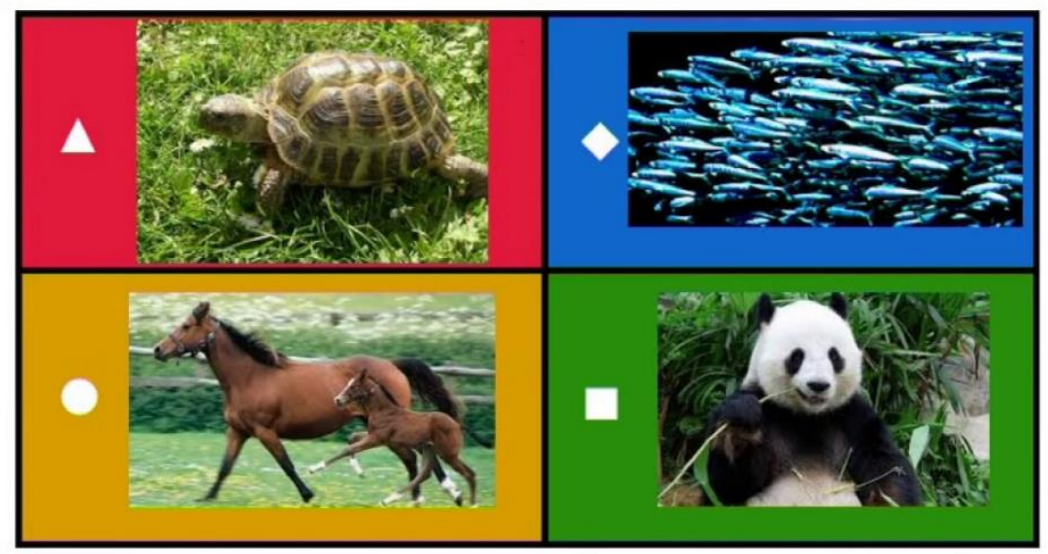

\subsubsection{ClassDojo}

It is a virtual resource especially for teachers, but a resource that can also be used by students and their families. Through this application and website we can communicate with the rest of the teachers, with the students and with the family.

ClassDojo is an application where each teacher can create their classroom and put emoticons on each child, which they or their families can change. It is a great tool to be able to manage the classroom in an attractive way for the little ones especially and, in addition, it is very easy to use. On the other hand, through this resource gamification is worked, since through positive and negative emoticons the teacher will be able to assign the student their behavior, their efforts, their tasks, the value to be highlighted of the day, the king of the order or even the rebel of the class.

As for how to work with this resource in the classroom, we can find a large number of functions, since it can be used to award students points for a series of behaviors, keep track of attendance, reward them with stars for completing tasks, To objectively evaluate the qualification criteria related to attitude, 
to choose a random student to carry out an activity, such as a timer, to project videos of ClassDojo characters where emotional intelligence is worked, etc.

In addition, in the same application, in the class history, all the projects or tasks carried out throughout the day can be uploaded. In this way, from home they will be able to remember what they have learned and parents will be able to keep track of the contents worked on day by day or upload activities, materials or songs that will be worked on the next day.

Image 2. Viewing the ClassDojo application

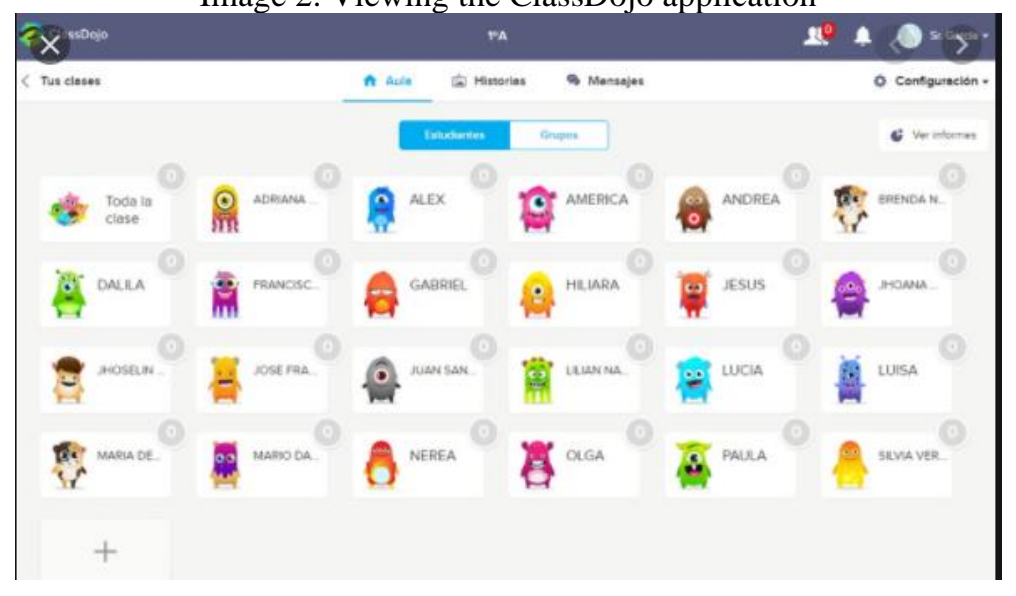

\subsubsection{Next 1.0 Edelvives Robotics}

This robot is a great tool to work on gamification in the classroom and to learn directional programming through the movements of the robot. This resource also includes programming cards to work the route before doing it and a large number of mats with contained numbers that are worked on in Early Childhood Education. In addition, it incorporates a workbook with different activities made up of nine missions and five challenges, with the aim of checking and reviewing the work done.

In the classroom, a presentation of the topic could be carried out and the students' previous knowledge would be worked on in order to increase their motivation. On the other hand, once the previous knowledge has been worked on, it will be to observe and recognize the concepts and vocabulary related to the topic. Once these aspects have been worked on, the robot is programmed through challenges, and the routes are carried out, after analysis and decision-making. Finally, we would proceed to the evaluation of what was learned. 
Image 3. Robotics Character Next 1.0.

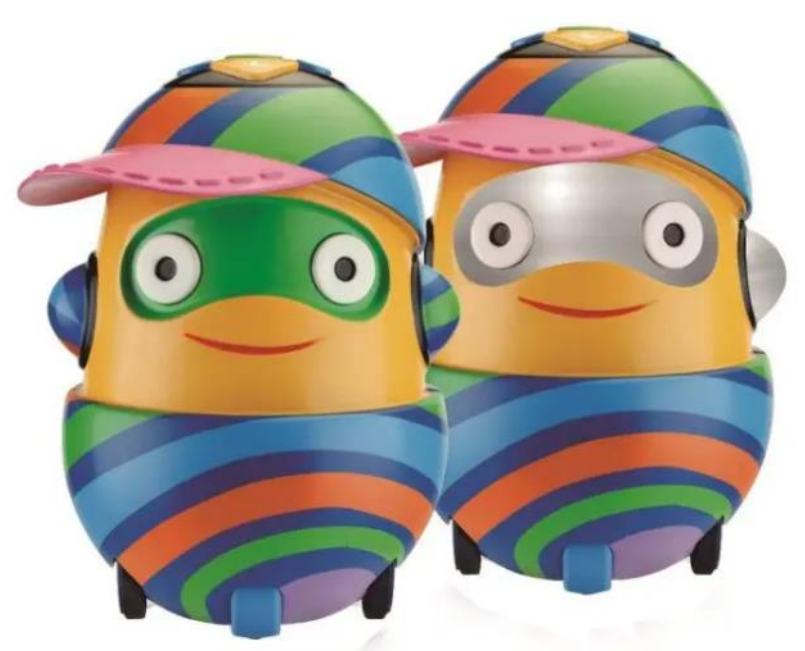

\section{METHODOLOGY}

For the development of gamification in the Early Childhood Education classroom, it is essential to attend to the methodological principles of gamification. In this way, it will be carried out successfully, thus reaching individual and collective competencies, at the same time that collaboration among the children in the classroom is favored.

To do this, we will attend the classification made by Barragán, Ceada, Andújar, Yrigoyen, Gómez and Artaza (2015), which details the characteristics of video games which, as teachers, we must adapt to the teaching-learning process (Romero and Espinosa , 2019). These are:

1. Gameplay: Take care of how to use the game, which should be easy and intuitive.

2. Collaboration between the players: The aim of the game is for the students to reach the goal set cooperatively, so there must always be more than one player.

3. Assume a role during the game: The student is a player whose role changes and evolves as he assumes different achievements and challenges and surpasses them.

4. Feedback: Must be present throughout the game.

5. Engagement: It refers to the degree of commitment that the player has. In other words, it attends to the degree of participation, motivation and activity shown during the course of the game.

6. Fun: This should be the protagonist during the teaching-learning process. Thus, the teacher will be able to attract the attention of his students, achieving significant learning.

\section{TEACHING ROLE AGAINST GAMIFICATION}

Teachers' literacy is essential so that they can adapt their teaching model to digital needs, thus avoiding falling into digital illiteracy. 
Today's children are born surrounded by technology and access it daily, so technological devices must also be used at school. In addition, it should be the first place where new technologies are used to promote learning in children.

Therefore, it is the teachers' task to provide different ways of presenting the content in class. Gutiérrez (2003), distinguished three essential dimensions in the training of teachers in the digitization and use of technologies (as cited in Ciganda, 2018):

- Knowledge and skills about the possibilities of ICT as teaching tools and resources used in the classroom.

- $\quad$ Hidden knowledge of the curriculum as well as the drawbacks of ICT and gamification.

- $\quad$ Knowledge of the contexts.

Of course, the teacher must make a change of role, since while traditional learning is standardized, individualistic, unidirectional and instructive and focuses on the teacher, interactive learning is personalized, participatory, collaborative and focuses on the student (Ciganda , 2018).

\section{ADVANTAGES AND DISADVANTAGES OF GAMIFICATION}

Specialists affirm that content gamification is a tool with great educational potential and a multitude of advantages: it favors socialization, the development of psychomotor and cognitive skills, the development of memory and visual skills, improvement in decision-making, increased capacity for conflict resolution, creativity (Ciganda, 2018). To all of them we must add those that are set out below:

- Motivation, since they increase the attractiveness of the activities, thus favoring the teachinglearning process.

- $\quad$ Technological literacy, developing skills in the use of computers, software and networks.

- $\quad$ The multitasking mentality, improving the ability to perceive various details from one or more screens.

- $\quad$ Teamwork, promoting communication with other colleagues.

- $\quad$ Individualized instruction, since the student is in charge of their own learning at their own pace.

In addition, gamification has several drawbacks, among which we highlight:

- Violence and aggressiveness.

- Competitiveness

- $\quad$ Wrong view of reality.

- Impulsiveness.

- $\quad$ Consumerism.

- $\quad$ It can encourage truancy. 
- It can favor the development of sedentary lifestyle, overweight and obesity.

- $\quad$ It can cause injury or discomfort to some parts of the body such as the eyes, wrists and / or back.

Despite this, most of the detailed drawbacks appear if there is excessive and uncontrolled use of video games. For this reason, it is essential to understand that gamification in the educational field is carried out under supervision by the teacher who, in addition, will control that the content present in the game is selected according to educational and didactic aspects (Ciganda, 2018).

\section{CONCLUSION}

Currently, we can see how new technologies are progressively being introduced into the classrooms and, as teachers, we are increasingly getting closer to new pedagogical technologies, much more adapted to self-motivation and self-learning, one of these pedagogical technologies, gamification. A current that vindicates the role of games and the fact of playing and having fun. Due to its great socializing capacity and its high power to motivate students, it makes it a clear tool to carry out in the classroom.

It is very important to show students at the time of working that not some simple contents that they have to memorize, but to make them see that they are able to assimilate the curricular proposal and take it as a personal challenge. Let us immerse ourselves in this world of pedagogical technologies, both we as teachers, as well as our students, in order to improve our teaching-learning strategies and with the aim of adapting to the characteristics, interests and needs of the Early Childhood Education stage, since As Astrid Lindgren well tells us, "Play, play and play, is there something in children's lives that could be more important? 


\section{REFERENCES}

Ciganda, I. (2018). Aspectos básicos de la gamificación en las aulas de Educación Infantil (Trabajo Fin de Grado). Universidad de Valladolid, Soria.

Contreras, R. S. y Eguia, J. (2016). Gamificación en aulas universitarias. Recuperado de: http://incom.uab.cat/download/eBook_incomuab_gamificacion.pdf.

Deterding, S., Khaled, R., Nacke, L. E. y Dixon, D. (2011). Gamification: Toward a Definition. En: Proceedings of the 2011 Workshop Gamification: Using Game Design Elements in Non-Game Contexts. Nueva York, NY: ACM. Recuperado de http://gamification-research.org/wpcontent/uploads/2011/04/02-DeterdingKhaled-Nacke-Dixon.pdf

Foncubierta, José Manuel, Rodríguez, Chema, Didáctica de la gamificación en la clase de español, Editorial Edinumen, 2014, consultado el 14 de diciembre de 2016, en https://www.edinumen.es/spanish_challenge/gamificacion_didactica.pdf.

Hamari,Juho, Jonna, Koivisto, "Social motivations to use gamification: an empirical study of gamifiyng excercise", en ECIS, 2013, paper 105, consultado el 12 de enero de 2017, en http://aisel.aisnet.org/cgi/viewcontent.cgi?article=1328\&context=ecis2013_cr.

Igado, M.F. (2013). La gamificación como motivación en los entornos virtuales de aprendizaje. Ludoteracy, creación colectiva y aprendizaje. II Congreso internacional Educación Mediática y Competencia Digital, La Rioja.

Romero, A., y Espinosa, J. (2019). Gamificación en el aula de Educación Infantil: un proyecto para aumentar la seguridad en el alumnado a través de la superación de retos. Edetania, 56, 61-82.

Simoes,Jorge, Díaz Redondo, Rebeca y Fernández Vilas, Ana, “A social gamification framework for a K6 learning platform”, Computers in Human Behavior, Elsevier, vol. 29, n 2, (2013), 345-353 